\title{
TRABALHO EM GRUPO COM ENLUTADOS
}

\author{
Melissa Pascoal
}

\begin{abstract}
RESUMO. A cada dia temos mais famílias vivenciando o luto gerado por homicídios, acidentes e violência, e isso tem causado alguns problemas psicológicos para as pessoas que estão nesta situação. Este artigo é um relato da experiência profissional vivida no Hospital e Maternidade Mauá com um grupo de autoajuda para pacientes em processo de luto, e seu objetivo é compartilhar a experiência e difundir este trabalho. Em 15 encontros pré-estruturados de acordo com a demanda apresentada pelo próprio grupo, foi possível trabalhar diversos temas relacionados à perda que influenciaram as participantes e ao mesmo tempo proporcionaram, além de conforto, uma possibilidade de identificação e troca, e consequentemente o ressurgimento da autoconfiança. Por meio da articulação da teoria com a prática, é evidenciado que o atendimento em grupo para enlutados é uma alternativa viável que trouxe resultados positivos e inspiradores e sua divulgação é importante para ampliar horizontes e criar novas possibilidades.
\end{abstract}

Palavras-chave: Morte; luto; grupo.

\section{WORK GROUP WITH BEREAVED}

\begin{abstract}
Every day we have more families experiencing mourning generated by homicides, accidents and violence, and this has caused some psychological problems for people in this situation. This study is a report of the professional experience at Hospital Mauá with a self-help group for bereaved patients, aiming to share the experience and disseminate this work. Through fifteen meetings pre-structured according to the demand of the group was possible to work various topics related to the loss, which have influenced the participants and at the same time provided comfort and a possibility of identification and exchange, and hence the resurgence of self-confidence in the participants. By means of the link theory with practice, it is evident that the group care for people in grief is a viable alternative that has brought positive and inspiring results, and its dissemination is important to broaden horizons and create new possibilities.
\end{abstract}

Key words: Death; bereavement; group.

\section{TRABAJO EN GRUPO CON ENLUTADOS}

RESUMEN. Cada día tenemos más familias que experimentan el luto generado por homicidios, accidentes y violencia, esto ha causado algunos problemas psicológicos para las personas que se encuentran en esta situación. Este artículo es un relato de la experiencia profesional vivida en el Hospital de Mauá con un grupo de autoayuda para pacientes en el proceso de luto, y su objetivo es compartir la experiencia y difundir este trabajo. A través de quince reuniones preestructuradas de acuerdo con la demanda presentada por el propio grupo, fue posible trabajar diversos temas relacionados a la pérdida que influyeron a las participantes y al mismo tiempo proporcionaron, además de confort, una posibilidad de identificación y cambio, y consecuentemente el resurgimiento de autoconfianza. A través de la articulación de la teoría con la práctica, es evidenciado que la atención en grupo para enlutados es una alternativa viable que trajo resultados positivos e inspiradores y su divulgación es importante para ampliar horizontes y crear nuevas posibilidades.

Palabras-clave: Muerte; luto; grupo.

Psicóloga do Hospital e Maternidade Mauá, especialista em Psicologia Hospitalar pela Santa Casa de Misericórdia de São Paulo (2009). 
A morte é um evento natural e faz parte do desenvolvimento humano. Mesmo assim, a maioria das pessoas sente-se incomodada quando convidada a falar sobre o assunto. Apesar deste receio, o evento da morte sempre gerou diversas perguntas.

Segundo Kovács (2003), a humanidade sempre se preocupou com o fim da existência. Diversos questionamentos foram e são feitos acerca da morte do outro ou mesmo da própria morte. Respostas foram produzidas pelas religiões, ciências, artes, filosofias, entretanto nenhuma delas é completa e universal.

Ariès (citado por Kovács, 2003) aponta que por um longo período histórico, a morte era anunciada por meio de um ritual, pois existia uma crença de que os mortos estavam presentes entre os vivos e seriam percebidos pelos que iriam morrer. A fronteira entre o natural e o sobrenatural não era claramente traçada. $\mathrm{O}$ doente estava no centro das pessoas e o maior temor que existia era o de morrer só. A morte era anunciada e não deveria ser inesperada, por isso os assassinatos e acidentes eram considerados desonrosos, pois não davam tempo para a pessoa se arrepender dos seus pecados. Por estas características que traziam familiaridade ao processo, a morte é denominada domada.

Até o início do grande desenvolvimento científico era a morte domada que fazia parte da vida das pessoas. Com o desenvolvimento das ciências médicas se observa uma grande mudança na representação da morte domada que vai se tornando selvagem. $\mathrm{O}$ modo como a pessoa viveu passa a ser o centro das atenções e o momento da morte passa a perder importância. $\mathrm{O}$ homem começa a manter distância da morte (Ariès citado por Kovács, 2003).

No século XIX, a morte passa a ser esperada como um porto seguro e surge o desejo de morrer. Era a morte cantada pelos poetas. Nesta época, a imagem da hora da morte era no leito, a repentina e solitária continuava sendo temida. No desenrolar do século XX, há uma inversão nas características da morte, pois passa a existir uma necessidade da morte ficar desapercebida, ou seja, que nada anuncie sua presença. Procura-se passar por este processo como se nada estivesse acontecendo. Este é o início de uma mentira, o de que a morte não existe. As pessoas não querem falar sobre o que está acontecendo com o doente, nem ele próprio, que sofre, mas nada diz, e o mais grave é que a morte é transferida para os hospitais. A morte passa a ser vista como suja e como um fracasso, um sinal de impotência ou imperícia da equipe médica (Ariès citado por Kovács, 2003).

$\mathrm{O}$ retrato da morte no final do século $\mathrm{XX}$ e início do XXI é a denominada morte escancarada. Este é o nome atribuído à morte que penetra na vida das pessoas a qualquer hora, invade e ocupa espaço. Ela dificulta o controle e as pessoas ficam expostas e sem defesas. Ela é repentina, invasiva e involuntária. São exemplos de morte escancarada os homicídios, alguns acidentes e a violência. (Kovács, 2003).

A natureza da morte pode ser esperada ou inesperada e pode ou não envolver um período de cuidados e preparo. As mortes súbitas pegam o indivíduo ou a família despreparados e esta acaba reagindo com choque. Não há tempo para despedidas ou para resolução de questões de relacionamentos. Pesquisas indicam que nestes casos a tristeza é maior do que nos casos de uma morte prolongada e natural. (Brown, 1995).

Com essa realidade temos cada vez mais famílias vivenciando perdas agressivas e devastadoras. São maridos, filhos, filhas, adultos e crianças que morrem das formas mais insólitas possíveis, e isso tem gerado graves problemas psicológicos para muitas pessoas que vivenciam esta situação.

Esslinger (2008) afirma que toda morte de um ente querido dá início ao processo de luto, em que determinadas reações são esperadas. A intensidade com que alguns sintomas aparecem pode indicar que o processo não está seguindo seu curso natural e o luto pode vir a tornar-se complicado. Para Esslinger, quando a morte que atinge a família é advinda de suicídio, ela reúne a maioria das características necessárias para um luto complicado: uma perda violenta e, em geral, não esperada.

Kovács (1992) complementa dizendo que quando a morte do outro acontece nas nossas vidas, ela traz à tona questões sobre o abandono e envolve a nossa consciência, o que acaba salientando a ausência e a separação da pessoa perdida. Kovács afirma ainda que o medo até hoje acaba sendo a resposta mais comum diante de uma perda.

Kubler.Ross (1981/2008) propõe uma sequenciação no processo de enfrentamento de perdas significativas. Os estágios descritos pela autora são a negação, em que o enlutado trata o fato como não existente; a raiva, impossibilitada de continuar com a negação para si mesmo a pessoa se sente tomada pela raiva; a barganha, em que há a tentativa frustrada de mudar o fato acontecido pelas trocas, principalmente com Deus; a depressão, fase na qual a pessoa se retrai e reflete sobre o acontecimento; e a aceitação, neste estágio o enlutado não sente a raiva, não nega $o$ acontecido e não tenta barganhar, ele refletiu sobre o acontecido e encontrou uma relativa calma interna.

Para Parkes (1998), as pessoas que enfrentam a perda de alguém vivenciam um momento de grande estresse que pode ser denominado como "crise". O traço mais característico no processo de luto são episódios agudos de dor, com muita ansiedade e dor psíquica em que o enlutado sente muita saudade da pessoa que morreu e chora ou chama por ela. Os episódios de dor começam algumas horas ou dias após a perda e chegam ao máximo entre cinco e 14 dias. De início são frequentes, mas conforme o tempo passa 
tornam-se menos frequentes e ocorrem somente quando provocados por algum estímulo. Para Parkes (1998), esta realidade pode colocar em risco a saúde mental do indivíduo em algum momento e nesses casos existe a necessidade de um trabalho psicológico.

Conforme pesquisas apresentadas por Parkes (1998), de uma forma ou de outra são as mulheres que sempre saem da experiência de luto com mais problemas psicológicos do que os homens.

O aconselhamento para o luto é oferecido por pessoas especializadas, como psicólogos, psiquiatras, assistentes sociais e são oferecidos para pessoas enlutadas que estão especialmente em risco após a perda. $\mathrm{O}$ aconselhamento é direcionado à família e pode ser feito de forma coletiva ou individual (Parkes, 1998).

Esta ajuda especializada é oferecida em alguns centros de estudo e ambulatórios hospitalares brasileiros, mas comumente oferecida em caráter individual.

Yalom (2006) afirma que a terapia de grupo é uma forma bastante efetiva de psicoterapia e é pelo menos igual à psicoterapia individual em sua capacidade de proporcionar benefícios significativos.

Conforme Osório (2007), algumas modalidades de terapia grupal não se sustentam em referenciais teórico-técnicos definidos e foram criados pela intuição e desejo de prospectar novas aplicações de seus criadores. Seus objetivos são mobilizar emoções e obter resultados supostamente terapêuticos.

Uma destas modalidades são os grupos de ajuda recíproca, ou autoajuda, na área de saúde que surgiram como desdobramentos do AA (alcoólicos anônimos) e tem como proposta implícita que os participantes ajudem uns aos outros. A força da motivação grupal é o principal instrumento de ação terapêutica. (Osório, 2007).

Yalom (2006) afirma que os grupos de autoajuda diferem dos grupos de terapia no sentido de que fazem muito menos interpretação da personalidade e há mais afirmações solidárias e positivas. Eles enfatizam o conhecimento interno em vez do externo e o contato com pessoas que atravessam problemas semelhantes instila esperança.

O grupo de autoajuda pode ser coordenado por profissionais da área de saúde ou por lideranças emergentes do próprio grupo de iguais, e podem ser ditos homogêneos ou de portadores de um sofrimento compartilhado, como grupo de obesos, hipertensos, diabéticos, asmáticos etc. (Osório, 2007). Yalom (2006) complementa dizendo que 50\% dos grupos de autoajuda têm algum tipo de liderança profissional.

Yalom (2006) afirma ainda que os membros valorizam muito o grupo e relatam ter mais capacidade de lidar com seus problemas, maior bem-estar e maior conhecimento sobre sua condição. Ele cita ainda dois exemplos de grupos de autoajuda para enlutados, Circle of Friends (para amigos de pessoas que cometeram suicídio) e Parents of Murdered Children (para pais de crianças assassinadas).

Com base na assistência psicológica prestada aos pacientes em processo de luto no ambulatório do Hospital e Maternidade Mauá, observa-se que inúmeros pacientes possuem histórias parecidas de perdas e se sentem solitários no compartilhamento das angústias e tristezas. Considerando este panorama foi proposta a realização de um grupo de autoajuda para estas pessoas objetivando maior efetividade do tratamento terapêutico para elaboração do luto.

Este artigo é um relato da experiência profissional vivida no Hospital e Maternidade Mauá e relata, além do referencial teórico encontrado, alguns trechos dos depoimentos das pacientes sobre suas perdas. É apresentado no texto o tema de cada sessão realizada além do conteúdo trabalhado e das colocações feitas pelas pacientes. $\mathrm{O}$ objetivo do artigo é compartilhar a experiência vivida e desta forma difundir a terapia em grupo para enlutados, um trabalho que é pouco realizado no Brasil e sobre o qual não encontramos muitas produções bibliográficas.

\section{CONTEXTO INSTITUCIONAL E FORMAÇÃO DO GRUPO}

O ambulatório do Hospital e Maternidade Mauá presta serviço aos pacientes encaminhados pela equipe médica do próprio hospital ou atende aos pacientes que procuram auxílio por conta própria. Os atendimentos psicológicos são na maioria das vezes realizados em caráter individual.

Em levantamento realizado pela equipe de psicologia, foi observada grande quantidade de pacientes em acompanhamento terapêutico individual no ambulatório por um período maior que seis meses e que apresentavam boa evolução do quadro, porém, permaneciam com a queixa constante de sentir solidão e não ter com quem compartilhar suas angústias. Os pacientes evitavam falar sobre a morte e seu sentimento de perda com o restante dos familiares, pois afirmavam que era preciso "poupá-los" do sofrimento.

Com base nestes preceitos, foi realizada uma triagem destes pacientes, excluindo-se aqueles com histórico de doença mental não-associada à perda. Foi exposto para os pacientes sobre o grupo e todos se disponibilizaram a fazer parte do mesmo.

O grupo foi composto com 12 mulheres entre 26 e 57 anos. Todas pacientes sofreram a perda do esposo, irmão ou filho nos últimos dez meses até o período de dois anos, e a causa das mortes foi suicídio, acidente de carro e homicídio.

O grupo foi fechado e teve a duração programada de 15 atendimentos que ocorreram entre o período de abril a 
setembro de 2010. O primeiro encontro foi pré-planejado e contou com o enquadre e a apresentação dos membros, em que cada pessoa pode compartilhar a sua história de perda. Os demais atendimentos foram montados conforme a demanda apresentada pelo próprio grupo e em comum acordo com o mesmo. Em cada dia, o tema foi trabalhado terapeuticamente, discutido e debatido entre as participantes e foi realizado um fechamento pelo terapeuta ao final, o que não impediu que o mesmo assunto retornasse para ser trabalhado novamente.

\section{RESUMO DAS SESSÕES}

Após o primeiro encontro, o tema escolhido para ser trabalhado foi a culpa. Muitas participantes se sentiam culpadas pela morte do outro, principalmente nos casos de suicídio e acidente.

Esslinger (2008) afirma que, por envolver um grande estigma, o suicídio gera sentimentos de culpa e vergonha que tendem a agravar o sofrimento.

As pacientes atendidas afirmavam que poderiam ter feito algo que impedisse, ou mesmo impossibilitado a pessoa de sair de casa naquele dia, ou então ela mesma não ter saído de casa para que "o pior" não tivesse acontecido. A culpa por não ter previsto ou percebido que algo ruim poderia acontecer se demonstrou bastante presente mesmo nos casos em que a morte havia ocorrido há mais tempo.

Algumas falas das pacientes que demonstram o tamanho da culpa que sentiam:

\begin{abstract}
"Eu não deveria ter saído naquele dia, tinha que ter ficado em casa, tinha que ter visto. Eu morava com ele, era minha obrigação ter percebido como ele estava." (perda do irmão por suicídio); " Quando ele saiu tínhamos brigado.Disse que tinha vontade de sumir, não voltar mais. Eu tinha que ter impedido ele de sair, em vez disso disse tomara que não volte mesmo. E aconteceu o que aconteceu, por minha culpa." (perda do esposo por acidente de carro).
\end{abstract}

Nos atendimentos seguintes, foi trazido e trabalhado pela terapeuta a proposta de Kubler.Ross(1981/2008) de sequência no enfretamento de perdas significativas. Todas as participantes do grupo se identificaram com as fases e conseguiram associar com sua história. Para muitas, era visível qual fase estavam enfrentando no momento e como isso mudava com o passar do tempo. Este trabalho foi bem intenso, valorizando $\mathrm{o}$ aspecto individual do sentimento de cada participante. Foi bastante salientado também que os estágios vão e voltam e que isso é normal e esperado.
Os trechos a seguir ilustram a identificação com as fases do luto: “Me sinto assim, desse jeito que você falou, com muita raiva. Sinto raiva do que aconteceu, raiva de mim e até raiva de Deus. É um desespero que demora pra passar." (perda do esposo por acidente de carro); "Nesses dois anos já senti tudo isso. Primeiro não queria acreditar, depois fiquei muito triste, depois com muita raiva. Mas hoje meu coração está calmo. Sinto uma paz quando penso em tudo" (perda do filho por homicídio), "Eu também já senti paz, mas de vez em quanto a raiva volta e toma conta de mim." (perda do esposo por homicídio).

No decorrer dos trabalhos, as participantes expressavam o quanto era importante para elas ter com quem dividir a angústia e, além disso, saber que existem outras pessoas com sentimentos e questionamentos parecidos.

O próximo tema trabalhado foi a comunicação com a família. Brown (1995) afirma que a morte ou doença grave de qualquer membro da família rompe o equilíbrio familiar.

Muitas das pacientes do grupo já se sentiam mais fortalecidas para falar com os familiares sobre a perda, como demonstram as falas a seguir: “... depois de estar aqui e ver que tem gente que sofre como eu, percebi que minha filha também está sofrendo por perder o pai e não conversar sobre isso. Agora sei que é melhor conversarmos e ajudar uma a outra." (perda do esposo por acidente de carro); "Tive medo de desabafar com nosso irmão e ele colocar a culpa em mim. Agora sei que é coisa da minha cabeça. Domingo a gente falou sobre a saudade e choramos junto. Tirei um peso grande das costas." (perda do irmão por suicídio).

Nos últimos encontros foram discutidos os ganhos que o atendimento em grupo trouxe, assim como questões sobre $\mathrm{o}$ futuro. $\mathrm{O}$ desligamento do ambulatório foi trabalhado com as pacientes que demonstraram aceitação e disseram se sentir confiantes e fortalecidas.

O $15^{\circ}$ atendimento foi de encerramento. Foi realizado um fechamento estruturado pela terapeuta. Todas as pacientes receberam a alta após este trabalho em grupo, porém o ambulatório do hospital ficou à disposição caso necessário. Até abril de 2011, nenhuma destas pacientes retornou ao ambulatório.

\section{RESULTADOS E DISCUSSÃO}

Dados encontrados na revisão bibliográfica mostram-se compatíveis com a prática clínica na qual evidenciamos que muitos pacientes que se encontram em processo de luto necessitam de acompanhamento psicológico. 
Parkes (1998) apresenta algumas pesquisas que referem que as mulheres sempre saem da experiência do luto com mais problemas psicológicos do que os homens. No ambulatório, verificamos que $98 \%$ dos pacientes atendidos com queixa de elaboração de luto são mulheres. Não podemos afirmar que, no geral, elas têm mais problemas psicológicos que os homens, mas nossos dados demonstram que as mulheres procuram mais ajuda do que os homens.

Conforme Esslinger (2008), quando um suicídio acomete uma família, o luto pode tornar-se complicado. Nas pacientes atendidas no grupo, verificamos que na maioria dos casos a morte foi ocasionada por suicídio (07 das 12 mulheres atendidas). Observamos que elas apresentaram maior quantidade de queixas, principalmente com relação ao fator culpa. Muitas se sentem mal por não ter percebido ou previsto o que aconteceria e acabam paralisando sua própria vida, sempre procurando uma resposta para o ocorrido. Confirmamos que o luto por suicídio é de fato complicado e é importante ter um trabalho direcionado nesta situação para auxiliar na resolução nos inúmeros conflitos que surgem.

Como todas as participantes perderam o parente de forma inesperada, observamos angústia e tristeza em todas, o que corrobora com os dados trazidos por Brown (1995). Mesmo as pacientes que haviam sofrido a perda há mais tempo, o sentimento de tristeza estava bastante presente. Podemos dizer que o tempo é algo que pode ajudar na elaboração do luto, mas isso vai depender muito mais da subjetividade, da história de vida e da rede de apoio daquela pessoa do que somente o fator tempo.

Com relação aos estágios do luto propostos por Kubler.Ross (1981/2008), observamos a manifestação de todos eles durante o período em que os trabalhos duraram, porém os mais frequentes foram a raiva, depressão e a aceitação. A discussão gerada pela apresentação das fases do luto proporcionou conforto para as pacientes. Muitas entendiam que o que sentiam não era normal, e após o conhecimento destas fases e de terem a informação de que se trata de um processo normal, além de poderem dividir as angústias com outras pessoas que passam por situações muito parecidas, puderam sentir calma e serenidade. Para algumas foi possível, pelo trabalho, atingir a fase de aceitação, em que ainda não tinham conseguido chegar. $O$ fornecimento da informação de que os outros estágios também podem voltar e que isso é esperado, trouxe para elas segurança para continuar com a vida.

Yalom (2006) fala sobre a efetividade da terapia em grupo. Neste trabalho pudemos observar que as pacientes encontravam-se, de certa forma, estagnadas na terapia individual. $\mathrm{O}$ trabalho em grupo pode proporcionar a divisão de sentimentos com pessoas que estavam passando pela mesma situação o que gerou conforto e contribuiu com a volta da confiança pela vida nestas mulheres. $\mathrm{O}$ trabalho em grupo para estas pacientes foi efetivo e trouxe mudanças significativas no quadro.

\section{CONSIDERAÇÕES FINAIS}

O trabalho em grupo para pacientes enlutados é ainda pouco realizado ou divulgado no Brasil. Essa experiência nos demonstrou que se trata de uma alternativa viável e que traz resultados positivos e inspiradores. O sofrimento trazido pela morte do outro pode ser o início de um amadurecimento emocional e o trabalho psicológico vem para auxiliar na construção desta nova realidade. A divulgação deste trabalho amplia horizontes e demonstra novas possibilidades.

\section{REFERÊNCIAS}

Brown, F. H. (1995). O impacto da morte e da doença grave sobre o ciclo de vida familiar. In B. Carter \& M. Mcgoldrick (Org.), As mudanças no ciclo de vida familiar (M.A.V. Veronese, Trad.). (pp. 393-407). Porto Alegre: Artmed.

Esslinger, I. (2008). O impacto do suicídio na família. In M. J. Kovács \& I. Esslinger (Org.), Dilemas Éticos. (pp. 23-30). São Paulo: Loyola.

Kovács, M. J. (1992). Morte e Desenvolvimento Humano. São Paulo: Casa do Psicólogo.

Kovács, M. J. (2003). Educação para a Morte: Temas e Reflexões. São Paulo: Casa do Psicólogo.

Kubler.Ross, E. (1981/2008). Sobre a morte e o morrer: o que os doentes terminais tem para ensinar a médicos, enfermeiras, religiosos e aos próprios parentes. ( $\mathrm{P}$. Menezes, Trad.). São Paulo: Editora WMF Martins Fontes. (Original publicado em 1981).

Osório, L. C. (2007). Grupoterapias, abordagens atuais. Porto Alegre: Artmed.

Parkes, C. M. (1998). Luto: Estudos sobre a perda na vida adulta. (M.H.P. Franco, Trad.). São Paulo: Summus.

Yalom, I. D. (2006). Psicoterapia de Grupo: Teoria e Prática. (R. C. Costa, Trad.). Porto Alegre: Artmed.

Recebido em 01-06-2011 Aceito em 26-06-2012

Endereço para correspondência: Melissa Pascoal. Rua Nubia, 190, Vila Nova Paulicéia, CEP 03267-090, São Paulo-SP, Brasil.

E-mail:mel_pascoal@yahoo.com.br. 